DOI: 10.1515/abcsj-2016-0015

\title{
Editorial
}

Many of us in the 'west', academics in particular, have the luxury of living in relative peace and security, shielded geographically from the turbulence, violence and poverty of many nations to the east. Few of us can ignore the inhospitable political status of Syria, Afghanistan, Eritrea and other countries whose wars, leadership and laws have led to the greatest movement of peoples since World War Two. Millions of people have made and continue to make the perilous journey west, in the hope of finding peace and prosperity, a place to raise families and form new communities. Community, what Zygmunt Bauman terms "the last relic of the old-time utopias of the good society" (Liquid Modernity 92), is in this sense an imagined new home in the west; a shelter in a foreign place.

The responses to this phenomenon are varied and complex; ongoing changes in the international political order make this an unstable terrain upon which to theorise. Yet, this mass migration impacts nations, communities, economies, and policies with wide-ranging consequences. Therefore we must attempt to make sense of the current wave of migration in an interdisciplinary and analytical mind-set. American studies and British studies scholars have theorised what it is that the west and western culture is thought to offer. Generally, there is a supposed heritage of social and ethical norms, religious and political systems with favourable moral traditions, customs and ethics which would ostensibly welcome newcomers and offer them both freedoms of thought, belief and movement as well as economic opportunities. The traditions of rationalism, scholasticism, humanism, and enlightenment purport to reflect a kind and thoughtful place of mutual respect and recognitions.

Migration has been a feature of human history from the earliest times; one might even say since the Homo sapiens left Africa 100,000 years ago. 
Yet the contemporary patterns of migration are inextricably linked to ideologies of places. The 'west' attracts several types of immigration at present, such as economic migrants and political refugees, thus complicating national and international policymaking. Thus, migration is bighly politicized and affects domestic and international politics, regional relationships and security policies. Among the analytical approaches, the economic one is useful in illustrating that there are both push and pull factors. 'Push' factors include a lack of economic opportunities, political or religious repression and demographic factors, and 'pull' factors include the demand for labour, economic opportunities, political or religious freedoms. Both macrostructures and microstructures have a part in how mass immigration plays out in the west. Macrostructures: made up of global markets, relationships among states, policies and laws, interact with microstructures: the internal networks created by immigrants, the relationships and communities they form, their help and information centres in host countries.

Two issues come to the fore of current analytic investigation: the regulation of international migration and the impact that the resultant ethnic diversity has on the culture of the destination countries. Immigration and the consequent ethnic diversity represent a serious challenge to national identity, in some sense creating a people without common ethnic origins. When this is coupled with a strong sense of national pride in the destination country, serious antagonism can be seen to occur. Transnationalism, as a field of study, examines the communities that result from the linkages being established between societies as a result of migration. This approach has much to offer as it helps to illustrate the way in which migrants often have multiple identities rather than a static national/ non-national identity.

\section{The Current Crisis}

The EU's external border force, Frontex, monitors the numbers arriving at Europe's borders. In 2015 the figure crossing into Europe was more than 
1,800,000. Between January and April of 2016, 135,711 people reached Europe by sea, according to the UNHCR, and the numbers continue to rise. The conflict in Syria appears to be the biggest driver of migration. However, political instability, poverty and ongoing violence in Afghanistan, Iraq, and Eritrea all contribute to large numbers of people on the move. Massive poverty in Kosovo is also pushing migration west. In 2015, images of bodies of drowned migrants on Mediterranean beaches brought publicity to the plight of these migrants, but the fear of such atrocities reaching British shores fuelled a spate of anti-immigration speeches.

According to the IOM, more than 3,770 migrants were reported to have died trying to cross the Mediterranean in 2015. In that year, the deadliest month for migrants was April, which saw a boat carrying about 800 people capsize in the sea off Libya. Overcrowding is thought to have been one of the reasons for the disaster. As academics, it is imperative that we reflect on this crisis as humanitarians and consider the appalling degradation and despair which compels people and families in such large numbers to make these dangerous journeys. In "From Pilgrim to Tourist," Bauman wrote of the nature of the necessary journey, the pilgrimage which is not a choice:

One can reflect on the road past and see it as progress towards, an advance, a coming closer to; one can make the distinction between 'behind' and 'ahead' and plot the 'road ahead' as a succession of footprints yet to pockmark the land without features. Destination, the set purpose of life's pilgrimage, gives form to the formless, makes a whole out of the fragmentary, lends continuity to the episodic. (22)

As these migrants and refugees continue to attempt to cross into Europe, mostly by sea, a European crisis has been sparked as countries struggle to cope with such large numbers, and divisions in the EU continue to flare up over how to efficiently manage the resettlement. Tensions in the $E U$ have been rising because of the burden faced by some countries; the UK 
has seen a rise in far-right politics espousing a 'true Britain' unsullied by immigrants.

The UK has opted out of any plans for a quota system but, according to Home Office figures, 1,000 Syrian refugees were resettled under the Vulnerable Persons Relocation scheme in 2015. Former Prime Minister David Cameron said the UK would accept up to 20,000 refugees from Syria over the next five years (Europe migrant crisis). However, the defeat of his party in the Brexit vote and his subsequent retirement from politics leaves this very much in doubt.

The rapid and unprecedented changes being experienced by Europe as migrants and refugees imprint Europe with a new identity opens up questions of European identity. The backlash seen in many European countries who openly reject migrants sparks fears of a right-wing takeover. Leonidas Donskis foresaw Europe's problems as the phenomena of fear of modernization, as mass migration would cause an "outbreak of moral panic and over-reaction" (in Bauman and Donskis 95).

Fear speaks the language of uncertainty, unsafety and insecurity, which our epoch provides in large quantities and even in abundance. The proliferation of conspiracy theories and vigorous, albeit simplistic, approaches to the European union reminds us of how difficult or even unbearable our life can be in constant doubt and uncertainty. (Donskis in Bauman and Donskis 96)

And yet, Britain attracts hundreds of thousands of migrants and refugees; their numbers growing even as the country's new Prime Minister assembles a squad of experts to orchestrate the official departure of the UK from the European Union. Focussing on salvaging access to the 'free market', the UK government so far refuses to confirm the status of the millions of EU citizens and the bundreds of thousands of refugees and migrants currently in the country. The Office of National Statistics state that 4.9 million people in the UK are non-British citizens. But what attracts 
these people? Current conditions in the Calais immigrant camp known as "the jungle" illustrate the severity with which Britain protects its borders from unwanted migrants. To use the Levi-Strauss term, Britain appears to enact an "anthropoemic" strategy, viewing potential immigrants as incurably alien to British values, beliefs and identity, barring them from entry without any sense of responsibility. The large numbers reaching Europe are seen to be the single biggest cause of Britain recently deciding to leave the European Union.

Writers, philosophers and academics speak of the crisis of liberalism in Europe: the counter-liberalism that sees xenophobia and racism on the increase, the rise in far-right parties and isolationist rhetoric, while politicians seek to publicise themselves on anti-immigration soapboxes in order to gain re-election. The United Kingdom voted with a majority of 52\% to leave the European Union on June 23rd, 2016. The political campaign leading to this decision was notable for its anti-European rhetoric, couched in the language of fear. British flags hang from windows as a mark of anti-European sentiment, political parties fail to reach any consensus over how to manage the exit from the EU and the new Prime Minister Teresa May faces continual attack over the mismanagement of the migrant crisis. Writing before the current crisis, Arjun Appadurai acknowledges the currencies of fear and distrust that characterise the contexts of rapid migration and refugee movement:

The speed and intensity with which both material and ideological elements now circulate across national boundaries have created a new order of uncertainty in social life... how many of "them" are now among us?... [t] hese various forms of uncertainty create intolerable anxiety about the relationship of many individuals to state-provided goods - ranging from bousing and bealth to safety and sanitation. (5-6)

As Britain grew to doubt the illusion of sovereignty, seeing it as ceded to the EU, an essential element of 'Britishness' was seen to be lost, and this 
was exacerbated by massive inward migration. Many of the discourses which abounded prior to the Brexit referendum centred on livelibood, security, pressure on health-care services and 'difference'. To use Appadurai's term, the "predatory narcissism" of the right-wing British populist politicians rendered foolish the millions of migrants who look to the west as a beacon of hope. Ethnic and religious difference has been seized as a defining factor in personhood, in rights and in national worthiness. And yet, these are not new concerns, nor are they limited to Britain as the papers in this edition attest. Migration has been a concern of nations and states since time immemorial and this is just one example of a time and place confronted by and concerned with mass migration toward economically preferential states.

This edition seeks to excavate some of these concerns and themes which circulate through cultural production in contemporary times. From Britain to Ireland and the USA, migration in its many guises catches the imagination as both gain and loss, a letting-go and a catching-hold, seeking to rebuild communities in strange places and to re-make selves in foreign contexts.

This special issue of American, British and Canadian Studies does not purport to offer any answers, nor any solutions. It seeks instead to contribute to the debate and engender new avenues of exploration so that we may adequately address this new social crisis. Reflecting on global mobility and cultural diaspora, on spaces, borders and transnationalism, it examines the European identity as it is imagined and mediated.

\section{Contributions}

The mediatisation of the current migrant crisis engenders much debate among media scholars. Ksenia Nikitina reflects on the current migration crisis as it exists not only in 'real' European countries, but in the information field as well. Media is responsible for the manner in which people from all over the world perceive the situation and so the media texts produced have both an agenda and a responsibility. This paper is devoted to the study of speech manipulation technologies in US political media discourse, examining a 
number of web-based articles. An axiological good/ bad dichotomy is exposed via a speech-manipulation analysis, which illustrates the non-neutral language of rapportage in contemporary media.

The global flow which operates in tandem with migration has profound consequences for national identities. Ching-huan Lin makes the valuable point that no single region in Europe is 'pure' and all have been at some time affected by immigration. This article explores the book A Distant Shore which focuses on the immigration of refugees to modern England in the late 1990s. By placing his protagonists within the wider context of the black (African-Caribbean) diaspora, the author has offered transnational perspectives on European migration and belonging that reflect, in turn, on what it means to be European at different stages of the continent's past. The arrivals of black migrants via various routes and at various times also reflect the successive changes in Europe's geopolitical map and its tight connection with the peripheral zones. The fluidity of Europe's borders, sense of identity and claims to space and certainty are exposed in this analysis, which offers valuable insights into the current predicament and our attempts to theorize it in concrete terms.

Art, as a cultural product, has much to add to discussions about identity and culture at any given time and place. Janna Hounen carefully examines empathy and benevolence by looking at two intermedial installations that address the experiences of people on the run from war or poverty, yet overtly hinder and problematize the viewer's identification with the depicted refugees. Friday Table (2013) by art collective Foundland, and Isaac Julien's video installation Ten Thousand Waves (2010) differ from the many contemporary discourses dealing with the migrant crisis, questioning the assumption of empathy's benevolence. Taking theoretical texts concerning the relation between empathy, politics and the (lens-based) representation of refugees by for instance Slavoj Žǐ̌ek (2016) and Jill Bennett (2005) as a starting point, Houwen reads Friday Table and Ten Thousand Waves as reflections on the pitfalls as well as the critical political possibilities of empathy. She contends that both texts feature intermediality as a system of 
observation. Both Friday Table and Ten Thousand Waves combine lens-based media (photography, video and film) with non-lens-based forms (drawings, graphs and calligraphy) and Houwen illustrates how this is crucial in the way that the artworks reflect on the complex nature of the relationship between spectators and depicted refugees.

Dana Radler makes a significant contribution to the field with her exploration of John McGahern's fiction. Memory, trauma, exile and conflict are examined via an investigation McGahern's work, looking at the personal memories and the question of what belonging and identity represent for the Irish. Radler shows the links between immigration and memory studies, psychology and psychoanalysis. These links are useful in clarifying how the immigrant can both love and hate his new territory. This exploration of transnationalism, as it is expressed through narrative fiction, looks at departure followed by return and the conflicting emotions of being a returning migrant. Radler exposes McGahern's writing as a blend of memories and imagination, and in so doing examines the pervasive power of ideologies which the migrant ingests abroad. This makes a robust contribution to the debate about identity and culture, the psychological residues of our economic choices in the light of 'hard times', and goes some way to explore the felt dimension of exile.

Transnationalism is a popular theme in many contemporary narratives; evoking many of the concerns and considerations which preoccupy today's post-migration citizens. Elena Stoican provides an interesting reflection on transmigrant cultural identities as illustrated in the works of two contemporary South Asian American and Romanian American authors, Jhumpa Lahiri and Aura Imbărus. This article offers useful examples of transnationalism and its often complex nature, as characters jostle with both their new and old cultural identities. The comparison involves Gogol, a South Asian American character, and Aura, the author of the memoir Out of the Transylvania Night. Although Gogol is a fictional character and Aura is an actual transmigrant, their comparative assessment relies on the assumption that both narratives are inspired by the authors' 
background of relocation. Despite their different cultural origins, both authors share thematic aspects related to the dynamics of cultural identity in the context of migration. This article contributes to the field of analysis by its lucid comparative analysis, which foregrounds intersections between different experiences of cultural negotiation in the context of displacement. Borm and raised in America, Gogol is challenged by his cultural multiplicity and he strives to suppress elements of his Indian identity. Aura Imbărus offers the example of a first generation Romanian transmigrant, who undergoes voluntary relocation to the United States. Both characters come to reassess the culture and value systems which they have ostensibly left behind, and finally adopt a bybridity which accommodates both the emigrant and immigrant. This article thus offers a critical lens with which to assess personhood and identity in the complex era of migration.

Jin Lee's research offers a unique perspective on current migrancy issues by looking at tensions between identity and difference through a reading of Arthur Conan Doyle's novella The Man with the Twisted Lip. Lee suggests that the story illustrates some of the tensions inherent in the notion of hospitality and invokes the Derridean notion of hospitality, in which identity and difference constitute each other. In examining the concept of global identity, Lee illustrates how this novella features global trade in miniature, and so can reveal patterns which are still prescient today, such as Britain's dependence on the Other.

\section{Works Cited}

Appadurai, Arjun. Fear of Small Numbers: An Essay on the Geography of Anger. Durham: Duke University Press, 2006.

Bauman, Zygmunt. Liquid Modernity [2 ${ }^{\text {nd }}$ Edition]. Cambridge: Polity, 2012. 
---. "From Pilgrim to Tourist - or a Short History of Identity" in Hall, S. \& du Gay, P. (2011) Questions of Cultural Identity. London: Sage, 1996.

Bauman, Zygmunt and Leonidas Donskis. Moral Blindness: The Loss of Sensitivity in Liquid Modernity. Cambridge: Polity, 2013.

"Europe migrant crisis." BBC News. British Broadcasting Corporation, 2016. Web. 9 Sept. 2016.

Frontex: European Border and Coast Guard Agency. Frontex, 2016. Web. 15 Sept. 2016.

SUSAN FLYNN

University of the Arts, London 